Jeffrey Shandler, Adventures in Yiddishland. Postvernacular Language \& Culture

Berkeley-Los Angeles-London, University of California Press, 2005, XV + $263 \mathrm{p}$.

Jacques Gutwirth

\title{
CpenEdition
}

Journals

Édition électronique

URL : http://journals.openedition.org/assr/3626

DOI : 10.4000/assr.3626

ISSN : $1777-5825$

Éditeur

Éditions de l'EHESS

Édition imprimée

Date de publication : 1 mai 2006

Pagination : 147-299

ISBN : 2-7132-2092-0

ISSN : 0335-5985

Référence électronique

Jacques Gutwirth, "Jeffrey Shandler, Adventures in Yiddishland. Postvernacular Language \& Culture », Archives de sciences sociales des religions [En ligne], 134 | avril - juin 2006, document 134-80, mis en ligne le 12 septembre 2006, consulté le 21 septembre 2020. URL : http://journals.openedition.org/ assr/3626 ; DOI : https://doi.org/10.4000/assr.3626

Ce document a été généré automatiquement le 21 septembre 2020.

(c) Archives de sciences sociales des religions 


\section{Jeffrey Shandler, Adventures in Yiddishland. Postvernacular Language \& Culture}

Berkeley-Los Angeles-London, University of California Press, 2005, XV + $263 \mathrm{p}$.

Jacques Gutwirth

1 Voici un livre de grande qualité qui présente et analyse, à de multiples niveaux, l'état actuel du yiddish qui, selon la thèse de l'auteur, est devenu « postvernaculaire »; cette langue, après avoir été longtemps d'usage vernaculaire - pratiquée dans la vie quotidienne - a désormais, et avant tout, de fortes dimensions et connotations symboliques, affectives et culturelles: " ... dans le yiddish postvernaculaire, le fait même que quelque chose est dit (ou écrit ou chanté) en yiddish, est, au moins aussi significatif que le sens des mots - sinon plus» (p. 22). Bien sûr, et J. Shandler le reconnaît, le yiddish continue d'être une langue vernaculaire, notamment dans les milieux ultra-religieux, surtout parmi les hassidim dont, il faut le souligner, le dynamisme démographique est certainement un élément de perpétuation et de développement, certes parmi une fraction limitée des juifs, du yiddish dans la vie quotidienne et l'éducation religieuse.

2 En vérité, le yiddish postvernaculaire se fonde sur la culture juive d'avant la Shoah, celle des quartiers juifs des petites et des grandes villes de Pologne, de Lituanie et d'autres régions proches, mais la Shoah a porté un coup presque mortel à cette culture et à cette langue qui a perdu presque tous ses locuteurs; néanmoins il persiste, principalement parmi les juifs américains, des traces de vocabulaire associés à de nombreuses références affectives. Par ailleurs, pour certains milieux attachés à cette langue «... le yiddish postvernaculaire se distingue de son usage vernaculaire, comme de celui d'autres langues utilisées par les juifs aujourd'hui dans la vie quotidienne, car il est surtout motivé par la volonté. De plus en plus, parler, lire, écrire - même écouter le yiddish, est devenu un acte électif» (p. 24). Les personnes intéressées fréquentent 
des festivals culturels yiddish, organisent des groupes de conversation, sauvent des livres yiddish abandonnés, etc.

3 L'objectif du livre est d'évaluer les changements que le yiddish a subi depuis la fin de la Seconde Guerre mondiale (p.30). Pari réussi: le livre est d'une singulière richesse quant aux divers aspects de ce yiddish postvernaculaire. L'auteur rappelle, opportunément, que le yiddishisme d'antan, c'est-à-dire l'aspiration à maintenir le yiddish comme langue juive, fut idéologiquement liée à la volonté de valider la vie juive en diaspora, alors que le renouveau de l'hébreu était intégré aux objectifs sionistes du retour en Terre sainte. Le yiddish post-vernaculaire d'aujourd'hui ne se veut pas nécessairement contestataire du sionisme et de l'hébreu, désormais pratiqué par des millions de personnes en Israël et ailleurs, mais il offre un modèle alternatif pour un foyer juif, un yiddishland qui peut s'épanouir partout, y compris en Israël. La persistance d'un yiddish postvernaculaire à travers le monde démontre, selon J. Shandler le pouvoir durable de cette langue, à la fois constante et changeante, symbole de la vigueur de la culture juive après la Shoah; on devine qu'il est très séduit par cette ténacité et son livre d'une certaine manière y contribue.

Le livre analyse, sur divers plans, l'activité "postvernaculaire ». Par exemple, en littérature : Isaac Bashevis Singer, prix Nobel de littérature en 1978, est essentiellement connu grâce aux traductions de ses livres, en premier lieu en anglais américain ; cellesci sont, d'ailleurs, de seconds originaux auxquels singer apportait son concours (les versions en d'autres langues découlent généralement du texte américain). Le monde yiddish de Singer, avec ses connotations diverses, se présente ainsi amplement à ses lecteurs. Une autre manifestation post-vernaculaire est la vogue, depuis les années 1970, de la musique « klezmer ». Les musiciens populaires d'autrefois jouaient, surtout, lors des mariages et restaient des figures marginales au sein de la judaïcité esteuropéenne. Aujourd'hui les klezmorim sont considérés comme des artistes créateurs et d'éminents porte-parole culturels rappelant, dans leurs représentations musicales et chantées, le monde yiddish d'avant la Shoah. L'auteur observe que, même si cela semble d'abord paradoxal (voir plus loin), les paroles yiddish des chants sont assez bien comprises sans paraphrases par un auditoire allemand non juif, alors que des traductions sont nécessaires pour les auditeurs américains, juifs et non juifs!

5 En revanche, si J. Shandler nous renseigne sur l'histoire du yiddish, il ne paraît pas avoir suffisamment pris en compte son caractère ambivalent. Langue formée à partir de l'allemand - sur lequel sa syntaxe s'est constituée - et de l'hébreu de la tradition religieuse, elle prend son plein essor au $\mathrm{xix}^{\mathrm{e}}$ et $\mathrm{xx}^{\mathrm{e}}$ siècles (jusqu'au génocide) dans des pays et régions non germaniques - Pologne, Biélorussie, Ukraine, Lituanie - tout en absorbant des éléments des langues locales. Le yiddish pratiqué dans les écoles juives ultra-religieuses de ces pays fonctionne déjà dans l'ambivalence car il se situe, essentiellement, au niveau oral, comme mode d'instruction et de commentaire du texte hébraïque. Aujourd'hui, les hassidim et certains ultra-orthodoxes, et d'autres milieux très circonscrits, tel le monde diamantaire à Anvers et à New York (qui d'ailleurs recouvre partiellement le secteur ultra-religieux) continuent à pratique le yiddish comme langue vernaculaire. Néanmoins, même dans ces milieux, le yiddish cède du terrain. Comme le montre l'auteur, aux États-Unis, dans les académies talmudiques ultra-orthodoxes, yeshives, s'est développé un nouveau langage, le yeshivish, qui fusionne l'anglais, le yiddish, l'hébreu moderne (israélien) et le loshen koydesh, littéralement la langue sainte, c'est-à-dire l'hébreu et l'araméen des Écritures et des 
rabbins commentateurs du Moyen Âge. En Israël, l'influence de l'hébreu moderne parlé pénètre aussi, inévitablement, dans les écoles et académies ultra-religieuses yiddishophones.

6 Isaac Bashevis Singer, admirable écrivain, déclarait lors de la cérémonie de réception du prix Nobel: «j'aime écrire des histoires de fantômes et rien ne va mieux à un fantôme qu'une langue mourante »(p. 180). Le yiddish meurt-il ? Ce n'est pas sûr mais, langue ambivalente dès l'origine, il est certainement fragile, malgré sa vitalité postvernaculaire et le fait qu'il reste, essentiellement, l'apanage des hassidim et de quelques autres groupes ultra-orthodoxes (représentant tout de même plusieurs centaines de milliers de personnes). Cependant, on l'a dit, l'hébreu moderne est désormais la langue de millions de juifs en Israël et il est largement enseigné dans les écoles judaïques à travers le monde.

7 Mes quelques observations critiques ne mettent nullement en cause l'excellence de ce livre. 